\title{
A reviravolta discursiva da Libras na educação superior
}

FAGNER CARNIEL

Universidade Estadual de Maringá, Maringá, PR, Brasil

\section{RESUMO}

$\mathrm{O}$ artigo analisa a recente inclusão da disciplina de língua brasileira de sinais (Libras) nos currículos das instituições de ensino superior do Paraná com o objetivo de discutir os seus principais sentidos e significados para a formação docente. Trata-se de uma investigação descritiva e exploratória que pretende apresentar um panorama regional do modo como a Libras está sendo organizada nesse estado para atender às exigências do decreto n. 5.626/2005. Para isso, serão apresentados os contextos políticos, intelectuais e pedagógicos que produziram a regulamentação do ensino da Libras na primeira década do século XXI, bem como seus impactos sobre a disseminação da surdez enquanto uma particularidade étnico-linguística passível de agenciamento e inclusão por parte das redes regulares de ensino.

PALAVRAS-CHAVE

currículo; ensino superior; políticas linguísticas; sociologia da educação; surdez. 


\title{
THE DISCURSIVE TURN OF BRAZILIAN SIGN LANGUAGE IN HIGHER EDUCATION
}

\begin{abstract}
The article analyzes the recent inclusion of the Brazilian Sign Language in the curriculum of higher education of Paraná in order to discuss their main ways and means for teacher training. Therefore, this is a descriptive and exploratory research that aims to provide a regional overview of how this sign language is being organized in this institutions to meet the requirements of decree n. 5,626/2005. For this, will be analyzed the political, the intellectual and the pedagogical contexts that produced the rules of BLS teaching in the first decade of this century, as well as its impact on the spread of deafness as an ethnic-linguistic peculiarity liable of agency and inclusion by regular education systems.
\end{abstract}

\section{KEYWORDS}

curriculum; higher education; linguistic policy; sociology of education; deaf.

\section{EL GIRO DISCURSIVO DE LA LENGUA BRASILEÑA DE SENALES EN LA EDUCACIÓN SUPERIOR}

\section{RESUMEN}

El artículo analiza la reciente inclusión de la lengua brasileña de señales (Libras) en los programas de las instituciones de educación superior de Paraná con el fin de discutir sus principales sentidos y significados para la formación docente. Se trata de una investigación descriptiva y exploratoria que pretende ofrecer un panorama regional de cómo la Libras está organizado en este estado para cumplir con los requisitos del decreto n. 5.626/2005. Por lo tanto, serán presentados los contextos políticos, intelectuales y educativos que promovieron las reglas de la enseñanza de Libras en la primera década de este siglo XXI, así como sus impactos en la propagación de la sordera como una peculiaridad étnica-lingüística que puede ser gestionada y contenida por los sistemas de educación regular.

\section{PALABRAS CLAVE}

plan de estudios; enseñanza superior; políticas lingüísticas; sociología de la educación; sordera. 
Cada lingua humana desafia a realidade de uma maneira que lhe é própria. [...] Cada lingua explora e transmite diferentes aspectos, diferentes potencialidades da circunstância bumana. Cada lingua tem suas próprias estratégias de negação e de imaginação. [...] É a profusão aparentemente perdulária das línguas que nos permite formularmos alternativas à realidade.

George Stainer, 2008, p. 99.

\section{APRESENTAÇÃO}

Costumam ser apenas quatro horas semanais, distribuídas ao longo dos últimos semestres das licenciaturas. Certamente não é o tempo necessário para tornar alguém proficiente em uma nova língua, sobretudo quando percebemos que essa língua permanece desconhecida pela grande maioria dos alunos e alunas que ingressam na disciplina. Mesmo assim, os atuais cursos de formação docente no Brasil parecem estar aproveitando a ocasião para criar uma abertura entre os seus variados conteúdos curriculares e proporcionar certo contato básico com a lingua brasileira de sinais (Libras). Muitas vezes, essa será a única experiência que esses graduandos e graduandas terão para vivenciar a Libras em sua trajetória acadêmica.

A jornada começa com os primeiros olhares, levados a capturar gestos e expressões faciais de uma gramática diferente das tradicionais línguas orais que as pessoas ouvintes aprendem durante a vida escolar. São movimentos corporais apresentados por quem ministra as aulas, em geral com o intuito de introduzir certo repertório semântico para preparar o novo aprendizado. Nessa direção, determinados léxicos vão sendo produzidos e reproduzidos no campo visual da sala, aula após aula, até virarem nomes, termos, unidades de sentido. Trata-se de uma forma de convencer ou seduzir as turmas a embarcarem na aventura de conhecer e se relacionar com a língua praticada pelas pessoas surdas no Brasil.

Antes de as aulas terminarem, é impossível saber o que irá se passar na cabeça dos milhares de acadêmicos e acadêmicas quando confrontados/as com a necessidade de utilizar e interpretar tantos sinais. Curiosidade, interesse ou hesitação? Ninguém consegue antecipar o resultado de experiências de ensino que, conforme Larrosa (2002), podem ser traduzidas pela metáfora de uma "travessia": tão apaixonante quanto perigosa. Afinal, o que acontece conosco mesmos quando somos desafiados ou desafiadas por formas gramaticais radicalmente distintas daquelas a que estamos habituados? O máximo que se pode afirmar no momento é que essas turmas irão experimentar, durante o curto período em que cursarão a disciplina, elementos gerais de uma língua descrita num espaço de enunciação que estará localizado logo à frente de seus corpos, como se fosse a extensão de sua superfície sensível, e terão a possibilidade de se relacionar com outras pessoas que também a praticam.

Desde de dezembro de 2005, com a publicação do decreto federal n. 5.626, a Libras tornou-se um componente curricular obrigatório para os cursos de licenciatura, de pedagogia e de fonoaudiologia do país. Após pouco mais de uma década de esforços e de lutas pela efetiva implementação dessa disciplina nas instituições de ensino superior, a língua de sinais e a própria história social da surdez começou 
a fazer parte do cotidiano acadêmico de uma parcela enorme de futuros professores e professoras. A expectativa oficial é de que o contato com tais conteúdos possa transformar a situação de desvantagem em que se encontram as pessoas surdas na sociedade e na educação básica brasileira. Para isso, entretanto, convém perguntar: Como essa disciplina está sendo organizada e que efeitos ela tem sido capaz de provocar sobre a formação docente?

Neste texto procuro refletir sobre essas questões com base na análise das matrizes curriculares dos cursos de licenciatura e das ementas das disciplinas de Libras nas principais universidades públicas do Paraná. Para isso, realizo um estudo descritivo e exploratório que pretende apresentar um panorama regional do modo como a Libras está sendo organizada nesse estado. Não se trata, portanto, de uma análise interessada em validar as dimensões linguísticas ou gramaticais frequentemente atribuídas a Libras, nem mesmo em avaliar a eficácia das estratégias didático-pedagógicas mobilizadas no seu ensino. $\mathrm{O}$ que tento problematizar são os principais sentidos e significados que essa língua adquiriu nas últimas décadas e que hoje compõem a gramática comum do seu ensino. Desse modo, espera-se contribuir com a investigação dos processos de produção de certa normatividade, ao mesmo tempo jurídica e pedagógica, que instituiu a Libras enquanto uma particularidade étnico-linguística merecedora de atenção e de controle por parte dos sistemas de ensino.

\section{A CAMPANHA PELA OFICIALIZAÇÃO DA LIBRAS NO BRASIL}

A trajetória da Libras no país foi oficialmente reescrita no dia 3 de abril de 2002, com a aprovação da Lei Ordinária Federal n. 10.436 - também conhecida como a lei de Libras (Brasil, 2002). Nesse dia, conforme observou Brito (2013), uma onda de euforia explodiu dentro e fora do Congresso Nacional. Militantes em defesa do reconhecimento da língua praticada pelas pessoas surdas comemoraram o resultado da votação como se ele simbolizasse uma espécie de "libertação". Isso porque a afirmação dessa língua, no entendimento dos movimentos sociais envolvidos na época, significava que os próprios grupos que a empregam seriam igualmente reconhecidos.

Passados vinte e um dias da aprovação da lei de Libras, em 24 de abril de 2002, a Presidência da República sancionou sua redação final (Brasil, 2002, p. 23), estabelecendo que:

Art. $1^{\circ}$ É reconhecida como meio legal de comunicação e expressão a Língua Brasileira de Sinais - Libras e outros recursos de expressão a ela associados.

Parágrafo único: Entende-se como Língua Brasileira de Sinais - Libras a forma de comunicação e expressão em que o sistema linguístico de natureza visual-motora, com estrutura gramatical própria, constitui um sistema linguístico de transmissão de ideias e fatos, oriundos de comunidade de pessoas surdas do Brasil. 
Conforme Assis Silva (2012, p. 27), a lei de Libras representou o "coroamento de um processo bastante complexo que envolveu diversos saberes e agentes que configuraram a surdez em termos de uma particularidade étnico-linguística". Do ponto de vista legislativo, sua regulamentação teve início com a apresentação do projeto de lei n. 131, em 13 de junho de 1996. Nesse projeto, a senadora Benedita da Silva, do Partido dos Trabalhadores (PT) do Rio de Janeiro, expressou a principal demanda dos coletivos liderados pela Federação Nacional de Educação e Integração de Surdos (FENEIS) que lutavam pelos direitos das pessoas surdas: a legitimação do estatuto linguístico da Libras no país.

Como demonstra a literatura especializada da área, os movimentos coletivos em defesa de uma perspectiva sociocultural da surdez haviam começado a se organizar no Brasil durante a passagem da década de 1970 para a década de 1980 (Lana Júnior, 2010). Naquele contexto de emergência, a reivindicação dos direitos linguísticos foi sendo lentamente elaborada como uma condição primordial para a consolidação da cidadania das populações falantes da língua de sinais. Tratava-se de uma percepção que apontava para a autonomia, a despatologização e o maior protagonismo dessas pessoas nos diversos espaços sociais em que estivessem inseridas. Sua construção, no entanto, seria o resultado da atuação de variados atores que militaram em espaços religiosos, escolares, acadêmicos e de gestão pública (Assis Silva, 2012; Carniel, 2013).

Entre esses atores, destaque particular pode ser atribuído ao coletivo surdo que se organizou para gerenciar a antiga Federação Nacional de Educação e Integração do Deficiente Auditivo (FENEIDA), criada em 1977, e transformá-la na atual FENEIS, com a presidência da intelectual e militante surda Ana Regina de Souza Campello, em 1983. Essa mudança não implicou apenas o empoderamento de representações surdas à frente da entidade, mas principalmente na oposição entre as noções de deficiência auditiva e de surdez, sendo esta última construída em torno das capacidades linguísticas e cognitivas dessas pessoas. Daquele momento em diante, a FENEIS atuou nas demais entidades e coletivos da área, congregando esforços para pressionar a administração pública a adotar políticas públicas de reconhecimento e de disseminação da Libras (Monteiro, 2006; Souza, 1998).

Segundo Brito, Neves e Xavier (2013, p. 67-68):

A Feneis foi a principal e maior organização do movimento social surdo, mas este incluiu também o agir coletivo de indivíduos vinculados a diferentes grupos e associações, tais como diversas associações de surdos, a Companhia Surda de Teatro, a Comissão Paulista para a Defesa dos Direitos dos Surdos, a Coalização Pró-Oficialização da Libras e o Grêmio Estudantil do Ines [Instituto Nacional de Educação de Surdos-RJ].

O campo de relacionamentos em que o movimento se constituiu foi, em larga medida, estruturado a partir da "comunidade surda", uma das categorias nativas forjadas e afirmadas pelo próprio movimento. 
Tal identidade coletiva, encarnada pela figura de uma comunidade surda nacional, conferiu materialidade e significado às ações dos coletivos no período, favorecendo e legitimando a produção de novos códigos culturais que questionaram os parâmetros então vigentes nos sistemas culturais e educacionais dominantes. Nesse processo, foi decisivo o desenvolvimento de um campo nacional de pesquisas sobre a estrutura linguística da Libras. De acordo com Quadros (2012), esses estudos desenrolaram-se durante a década de 1980 por meio de pesquisas como as de Lucinda Ferreira Brito, na Universidade Federal do Rio de Janeiro (UFRJ). Além da descrição dos aspectos gramaticais dessa língua, a pesquisadora também iniciou investigações acerca de suas propriedades fonológicas e de suas características pragmáticas (Brito, 1984, 1990, 1995).

Desse modo, até meados da década de 1990, como observou Souza (1998, p. 103), acadêmicos e acadêmicas vinculados/as ao campo da linguística exerceram um papel político fundamental na área, pois "coube a eles [e a elas] endossar, como especialistas, a 'legitimidade linguística' da Libras". Brito, Neves e Xavier (2013, p. 95) também notam o adensamento de estudos sobre a estrutura linguística da língua de sinais, informando que:

As interações entre intelectuais e ativistas surdos ou ouvintes que se afirmaram como militantes do movimento social surdo ocorreram nas cidades de Porto Alegre, Rio de Janeiro (onde foram mais fortes), São Paulo e Campinas, respectivamente em torno de iniciativas promovidas pela Escola Especial Concórdia e de atividades de pesquisa, ensino e extensão, desenvolvidas por professores e pesquisadores da Universidade Federal do Rio de Janeiro (UFRJ), da Universidade Estadual do Rio de Janeiro (UERJ), da Pontifícia Universidade Católica de São Paulo (PUC-SP) e da Universidade Estadual de Campinas (Unicamp). Destacou-se, na segunda metade da década de 1980, o papel do Grupo de Estudo sobre Linguagem, Educação e Surdez (GELES), cujos pesquisadores se dividiram em subgrupos com atuação em Pernambuco, na Universidade de Pernambuco (UPE), no Rio, na UFRJ e, em Campinas, na Unicamp. Posteriormente, a partir de meados dos anos 1990, essa interação se expandiu e se intensificou na região Sul, principalmente nos grupos de pesquisa vinculados à Universidade Federal do Rio Grande do Sul (UFRGS) e à Universidade Federal de Santa Catarina (UFSC).

Simultaneamente a essa explosão discursiva em torno do estatuto linguístico da Libras, intelectuais de diversas outras áreas do conhecimento foram se aproximando da discussão e procuraram transpô-la às demais esferas da vida social, em especial à esfera educacional. Dessa maneira, por volta do final da década de 1980, formou-se um novo campo multidisciplinar de estudos surdos. Conforme Skliar (1998, p. 29):

Os Estudos Surdos em Educação podem ser pensados como um território de investigação educacional e de proposições políticas que, através de um conjunto de concepções linguísticas, culturais, comunitárias e de identidades, definem 
uma particular aproximação — e não uma apropriação — com o conhecimento e com os discursos sobre a surdez e o mundo dos surdos.

Nesse contexto, inúmeras investigações acerca da surdez voltaram-se fortemente às especificidades socioculturais dos coletivos surdos e às controvérsias pedagógicas implicadas em sua escolarização. Assim, na entrada dos anos de 1990, em um período marcado por reformas substanciais na administração estatal brasileira, uma nova arena de atuação pôde ser configurada: as secretarias de educação básica e os departamentos de educação especial espalhados por todos os estados e municípios do país. Desses espaços institucionais participaram profissionais, intérpretes e intelectuais vinculados à área que progressivamente passariam a formular as primeiras políticas em favor do bilinguismo na educação de pessoas surdas produzindo, então, uma tradução das noções de surdez e de cultura surda para os contextos da gestão educacional (Carniel, 2013).

Portanto, a participação das inúmeras lideranças que orbitaram em torno da defesa dos direitos linguísticos e da cidadania surda ao longo das décadas de 1980 e de 1990 parece ter contribuído para a contemporânea reconfiguração dos discursos sobre a surdez e a língua de sinais. Tal reconfiguração encontrou nas noções de comunidade, cultura e identidade surda uma narrativa suficientemente forte para deslocar a surdez do campo discursivo da deficiência auditiva e recolocá-la enquanto uma expressão não apenas linguística, mas também étnica, assegurando uma pauta identitária legítima para a campanha de oficialização que culminaria na promulgação da lei de Libras, em 2002. Desde então, tal dispositivo jurídico tem operado como uma poderosa ferramenta política que fortaleceu a enunciação da Libras enquanto um sistema linguístico particular, bem como a visibilização de um sujeito coletivo para ativá-la: a comunidade de pessoas surdas.

\section{LIBRAS NO ENSINO SUPERIOR: NORMATIZAÇÕES E TENSÕES}

A principal conquista da promulgação da lei de Libras no Brasil certamente está relacionada com o direito de as pessoas surdas falarem a língua de sinais, em qualquer espaço público em que estiverem, como uma língua nativa (Souza, 2006). Esse direito foi postulado em uma conjuntura nacional e internacional favorável ao reconhecimento das diferenças culturais de grupos historicamente marginalizados ou excluídos, nas quais se atribuiu à educação um papel central na promoção da cidadania e da justiça social (Candau, 2008). Nesse sentido, a oficialização da Libras na primeira década do século XXI reativou debates em torno dos caminhos pedagógicos para promover a inclusão das pessoas surdas nos sistemas de ensino. De acordo com a intelectual e militante surda Strobel (2006, p. 244):

A educação inclusiva é um fato imposto em muitos países, inclusive no Brasil; entretanto, historicamente, veremos que tem havido fracasso na educação de surdos. Por que este fracasso escolar? Apesar dos nossos esforços em educar os sujeitos surdos durante muitos séculos de atendimento e reabilitação da fala, ocorreu um desequilíbrio, gerado pela não escolarização efetiva dos mesmos. 
Para a autora, o aparente "fracasso escolar" das comunidades surdas estaria relacionado com o fato de as próprias instituições escolares, atualmente apresentadas como inclusivas, terem sido constituídas por meio de perspectivas "não surdas". Ou seja, são espaços que historicamente negaram, inferiorizaram ou patologizaram a surdez e, mesmo quando se preparam para abrigar uma educação voltada a essa categoria social, o fazem a partir de narrativas pedagógicas que desconsideram os códigos e os circuitos culturais que produzem a surdez enquanto uma diferença, ao mesmo tempo linguística, cultural e política. Desse modo, a partir de 2003, a FENEIS e os demais coletivos da área ligados aos programas do Ministério da Educação de formação e disseminação da língua de sinais passariam a pressionar a gestão pública em busca de uma regulamentação para a lei de Libras, principalmente no campo educacional (Felipe, 2006).

Tal regulamentação ocorreu apenas em 22 de dezembro de 2005, por meio do decreto federal n. 5.626. Entre os diversos dispositivos instaurados por essa normativa oficial (Brasil, 2005, p. 28), destaque particular pode ser atribuído à presença da Libras nos currículos do ensino superior do país:

Art. 3o A Libras deve ser inserida como disciplina curricular obrigatória nos cursos de formação de professores para o exercício do magistério, em nível médio e superior, e nos cursos de Fonoaudiologia, de instituições de ensino, públicas e privadas, do sistema federal de ensino e dos sistemas de ensino dos Estados, do Distrito Federal e dos Municípios.

A novidade legislativa estabeleceu que, a partir de 2006, todas as instituições de ensino superior teriam um prazo de dez anos para incluir progressivamente a disciplina de Libras como componente curricular obrigatório em seus cursos de licenciatura, de pedagogia e de fonoaudiologia - e a língua de sinais deveria ser pensada como um objeto de ensino, pesquisa e extensão. Para viabilizar essa iniciativa, o Ministério da Educação promoveu programas específicos de fomento que incentivassem a abertura de novas graduações e programas de pós-graduação para pessoas surdas e ouvintes. O objetivo oficial seria o de formar profissionais, tanto docentes quanto tradutores e intérpretes, capazes de promover a inclusão escolar desse segmento social. Desenhou-se, portanto, um cenário promissor para a contratação de falantes da língua de sinais (surdos e ouvintes) nos espaços escolares e acadêmicos do país, bem como ao ingresso de estudantes surdos ou surdas e à difusão social da Libras.

Entre os efeitos mais notáveis dessas políticas afirmativas, esteve a criação do primeiro curso de graduação em letras Libras do Brasil, em 2006, sediado na Universidade Federal de Santa Catarina (UFSC). Esse curso foi organizado originalmente como uma licenciatura com o intuito de habilitar futuros professores e professoras proficientes em língua de sinais na modalidade à distância. Em sua primeira edição, ele atendeu aproximadamente quinhentos graduandos e graduandas distribuídos/as em nove polos vinculados a outras universidades públicas do país. Pouco tempo depois, em 2008, o curso seria ampliado para habilitar bacharéis especializados em tradução e interpretação 
da língua de sinais. Como relatam algumas de suas idealizadoras (Quadros e Stumpf, 2009, p. 183-184):

Espera-se, através do desenrolar deste curso, que se inicie um processo intelectual maior no contexto nacional, e que sejam possibilitadas ainda mais criações que colaborem para a inserção social do surdo. [...] pode-se concluir que o campo de pesquisa que se abre dentro do Curso de Letras Libras, incluindo o ambiente virtual, a tradução dos materiais para Libras, a produção de vídeos para o ambiente e para os DVDs do curso Letras Libras e as videoconferências, é cada vez mais amplo, graças aos resultados obtidos e à possibilidade de ter uma resposta imediata dos usuários do ambiente, os próprios surdos. Dessa forma, constrói-se um curso "surdo" visto e revisto pelos próprios surdos.

Com o objetivo de impulsionar a nova matéria, o Ministério da Educação também se engajou em financiar e distribuir inúmeras publicações da área. Entre os anos de 2006 a 2010, por exemplo, foram editados e reeditados diversos livros e materiais didáticos que, desde então, vêm servindo de apoio ao ensino da Libras enquanto segunda língua - como o manual didático Libras em contexto, em circulação desde 1997 -, ou mesmo para a consulta e a atualização acerca dos principais debates empreendidos na área - como a série de pesquisas "Estudos Surdos", organizada desde 2006 pelo programa de letras Libras da UFSC. Nessa direção, durante a primeira década do século XXI reuniu-se no Brasil um volumoso repertório de artefatos pedagógicos que norteariam e credenciariam o ingresso de profissionais aptos ao ensino dessa língua nas mais variadas instituições de ensino superior.

De fato, a abertura de vagas de trabalho e o desenvolvimento de materiais didáticos voltados à formação docente provocou a criação de inúmeros outros cursos de graduação e de pós-graduação, em instituições públicas e privadas, que visaram atender às exigências do decreto n. 5.626 de 2005. Em que pesem as controvérsias a respeito da comercialização da Libras no país (Martins e Nascimento, 2015), parece inegável que a legislação vigente vem promovendo mudanças consideráveis no estatuto da surdez e da língua de sinais. Segundo Martins (2008, p. 199), a entrada da Libras no ensino superior teria o potencial de gerar descentramentos que "oferecem ao surdo [e à surda] um lugar de discurso, o poder da fala e a autoridade no processo do ensino de ouvintes".

No entanto, ainda que a disciplina tenha sido introduzida nos currículos universitários, favorecendo certa circulação de pessoas, saberes, e algum espaço para a enunciação da língua de sinais no universo acadêmico, a dúvida permanece: o que podemos esperar de uma única disciplina quando ela parece estar "desconectada" do restante das atividades formativas dos cursos? Ora, perceber a maneira pela qual esses conteúdos estão sendo incluídos nos currículos do ensino superior torna-se uma questão decisiva para compreendermos o lugar simbólico concedido às narrativas surdas. Sobre isso, Martins (2012) já alertou para o fato de que a padronização e a instrumentalização do ensino de Libras poderia levar antes à sua "folclorização" do que ao reconhecimento das diferenças representadas pela surdez na produção do conhecimento. 


\section{A ORGANIZAÇÃO CURRICULAR DA LIBRAS NO ENSINO SUPERIOR PARANAENSE}

O estado do Paraná conta atualmente com onze universidades públicas, sete estaduais e quatro federais, que habilitam todos os anos milhares de docentes para atuarem nas variadas disciplinas que integram os currículos regulares da educação básica brasileira. Por meio de um levantamento descritivo dos projetos pedagógicos disponibilizados nos portais dessas instituições - a Universidade Estadual do Norte do Paraná (UENP) foi a única cujos dados não puderam ser acessados constatou-se que, a partir de 2016, a disciplina de Libras ingressou fortemente nas diferentes matrizes curriculares das licenciaturas. Uma vez que o objetivo dessa análise recai sobre os sentidos e significados que a língua de sinais vem adquirindo na formação de docente, foram excluídas informações referentes aos cursos de pedagogia e de fonoaudiologia.

A intenção de reunir e analisar tais informações advém da possibilidade de realizar um balanço regional da situação da disciplina nas universidades públicas paranaenses. A expectativa é a de que este estudo exploratório permita futuras comparações ou mesmo oriente outras investigações a respeito de experiências de ensino particulares. Nesse sentido, o Quadro 1 tem o objetivo de apresentar um panorama geral dos modos pelos quais o ensino de Libras está estruturado nesse estado. Cabe destacar que tais informações foram selecionadas para representar exemplos concretos de como a língua de sinais figura nos demais cursos de formação docente de cada universidade, uma vez que sua organização teria sido elaborada e padronizada pelos respectivos departamentos de educação e implantadas externamente nas matrizes curriculares das licenciaturas.

Desse modo, o Quadro 1 agrupa dados oferecidos por dez das onze instituições públicas de ensino superior do estado - Universidade Federal do Paraná (UFPR), Universidade Tecnológica Federal do Paraná (UTFPR), Universidade Federal da Fronteira Sul (UFFS) e Universidade Federal da Integração Latino Americana (UNILA), Universidade Estadual de Maringá (UEM), Universidade Estadual de Londrina (UEL), Universidade Estadual de Ponta Grossa (UEPG), Universidade Estadual do Oeste do Paraná (UNIOESTE), Universidade Estadual do Centro-Oeste (UNICENTRO) e Universidade Estadual do Paraná (UNESPAR). Nele, é possível visualizar nomenclaturas, cargas horárias, períodos de oferta e ementas das disciplinas oferecidas em cursos de licenciatura selecionados.

Um aspecto a ser considerado nessas estruturações curriculares diz respeito à variedade de maneiras pelas quais a disciplina é organizada. Em geral, a disciplina figura nos anos finais das licenciaturas, mas também aparece na primeira metade de três dos dez cursos considerados. Sua carga horária varia entre 51 horas e 72 horas (quando ministradas em duas disciplinas semestrais de 36 horas). As nomenclaturas, apesar de diversas, fazem menção direta à Libras. Entretanto, o que realmente chama atenção é a multiplicidade de ementas, pois parecem expressar, em alguma medida, a variedade de perspectivas que, desde meados da década de 1970, estive sendo formulada e articulada no Brasil para promover a emergência da surdez enquanto uma nova categoria social e pedagógica. A ativação de um "sujeito surdo", nesse 


\section{Quadro 1 - Caracterização das disciplinas de Libras no ensino superior paranaense}

\begin{tabular}{|c|c|c|c|c|c|}
\hline IES & Curso & Disciplina & $\begin{array}{c}\text { Carga } \\
\text { horária }\end{array}$ & Período & Ementa \\
\hline 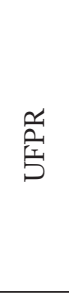 & $\begin{array}{l}\text { Ciências } \\
\text { biológicas }\end{array}$ & $\begin{array}{c}\text { Comunicação } \\
\text { em língua } \\
\text { brasileira } \\
\text { de sinais }\end{array}$ & $60 \mathrm{~h}$ & $8^{\circ}$ & $\begin{array}{l}\text { A compreensão histórica } \\
\text { das comunidades surdas e } \\
\text { de sua produção cultural. } \\
\text { Bilinguismo e educação de } \\
\text { surdos: diretrizes legais e } \\
\text { político-pedagógicas. Aspectos } \\
\text { linguísticos da língua de sinais } \\
\text { brasileira: teoria e prática. }\end{array}$ \\
\hline \multirow{2}{*}{ 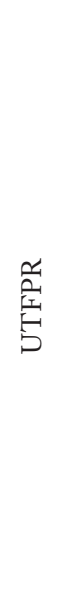 } & \multirow{2}{*}{ Matemática } & Libras 1 & $36 \mathrm{~h}$ & $3^{\circ}$ & $\begin{array}{l}\text { Línguas de sinais e minoria } \\
\text { linguística; as diferentes línguas } \\
\text { de sinais; status da língua de } \\
\text { sinais no Brasil; cultura surda; } \\
\text { organização linguística da Libras } \\
\text { para usos informais e cotidianos: } \\
\text { vocabulário; morfologia; sintaxe } \\
\text { e semântica; a expressão corporal } \\
\text { como elemento linguístico. }\end{array}$ \\
\hline & & Libras 2 & $36 \mathrm{~h}$ & $4^{\circ}$ & $\begin{array}{l}\text { A educação de surdos no Brasil; } \\
\text { cultura surda e a produção } \\
\text { literária; emprego da Libras em } \\
\text { situações discursivas formais: } \\
\text { vocabulário; morfologia; } \\
\text { sintaxe e semântica; prática } \\
\text { do uso da Libras em situações } \\
\text { discursivas mais formais. }\end{array}$ \\
\hline 恐 & $\begin{array}{l}\text { Letras } \\
\text { português- } \\
\text { espanhol }\end{array}$ & $\begin{array}{c}\text { Língua } \\
\text { brasileira de } \\
\text { sinais (Libras) }\end{array}$ & $60 \mathrm{~h}$ & $8^{\circ}$ & $\begin{array}{l}\text { Visão contemporânea da } \\
\text { inclusão e da educação } \\
\text { especial na área da surdez. } \\
\text { Cultura e identidade da pessoa } \\
\text { surda. Tecnologias voltadas } \\
\text { para a surdez. História da } \\
\text { linguagem de movimentos e } \\
\text { gestos. Breve introdução aos } \\
\text { aspectos clínicos, educacionais } \\
\text { e sócio-antropológicos } \\
\text { da surdez. Características } \\
\text { básicas da fonologia de } \\
\text { Libras: configurações de mão, } \\
\text { movimento, locação, orientação } \\
\text { da mão, expressões não manuais. } \\
\text { O alfabeto: expressões manuais } \\
\text { e não manuais. Sistematização } \\
\text { e operacionalização do léxico. } \\
\text { Morfologia, sintaxe, semântica } \\
\text { e pragmática da Libras. } \\
\text { Diálogo e conversação. Didática } \\
\text { para o ensino de Libras. }\end{array}$ \\
\hline
\end{tabular}


Quadro 1 - Continuação

\begin{tabular}{|c|c|c|c|c|c|}
\hline IES & Curso & Disciplina & $\begin{array}{c}\text { Carga } \\
\text { horária }\end{array}$ & Período & Ementa \\
\hline \multirow[b]{2}{*}{ 岕 } & \multirow[b]{2}{*}{ História } & Libras 1 & $36 \mathrm{~h}$ & $3^{\circ}$ & $\begin{array}{c}\text { Fundamentos filosóficos e } \\
\text { sócio-históricos da educação } \\
\text { de surdos: história da educação } \\
\text { de surdos. Sociedade, cultura e } \\
\text { educação de surdos no Brasil. As } \\
\text { identidades surdas multifacetadas } \\
\text { e multiculturais. Modelos } \\
\text { educacionais na educação de surdos. } \\
\text { Estudos linguísticos da língua } \\
\text { brasileira de sinais: introdução às } \\
\text { práticas de compreensão e produção } \\
\text { em Libras através do uso de } \\
\text { estruturas e funções comunicativas } \\
\text { elementares: sistema fonológico, } \\
\text { morfológico, sintático e lexical } \\
\text { da Libras, bem como o uso de } \\
\text { expressões faciais gramaticais } \\
\text { e afetivas (nível iniciante). }\end{array}$ \\
\hline & & Libras 2 & $36 \mathrm{~h}$ & $4^{\circ}$ & $\begin{array}{l}\text { Didática e educação de surdos: } \\
\text { processo de aquisição da língua } \\
\text { materna (L1) e da língua } \\
\text { portuguesa (L2) pelo aluno surdo. } \\
\text { As diferentes concepções acerca do } \\
\text { bilinguismo dos surdos. O currículo } \\
\text { na educação de surdos. O processo } \\
\text { avaliativo. O papel do intérprete } \\
\text { de língua de sinais na sala de } \\
\text { aula. Legislação e documentos. } \\
\text { Prática de compreensão e } \\
\text { produção da Libras através do } \\
\text { uso de estruturas em funções } \\
\text { comunicativas: morfologia, sintaxe, } \\
\text { semântica e a pragmática da Libras. } \\
\text { Aprimoramento das estruturas da } \\
\text { Libras. Escrita de sinais. Análise } \\
\text { reflexiva da estrutura do discurso } \\
\text { em língua de sinais e da variação } \\
\text { linguística (nível intermediário). }\end{array}$ \\
\hline$\sum_{\text {空 }}^{5}$ & $\begin{array}{c}\text { Ciências } \\
\text { sociais }\end{array}$ & $\begin{array}{l}\text { Introdução } \\
\text { à Libras }\end{array}$ & $68 \mathrm{~h}$ & $8^{\circ}$ & $\begin{array}{l}\text { Estudo e prática da língua } \\
\text { brasileira de sinais (Libras). } \\
\text { Instrumentalizar os graduandos } \\
\text { para o estabelecimento de } \\
\text { uma comunicação funcional } \\
\text { com pessoas surdas. Favorecer } \\
\text { a inclusão da pessoa surda no } \\
\text { contexto escolar. Expandir o uso } \\
\text { da Libras legitimando-a como a } \\
\text { segunda língua oficial do Brasil. }\end{array}$ \\
\hline
\end{tabular}

Continua... 
Quadro 1- Continuação

\begin{tabular}{|c|c|c|c|c|c|}
\hline IES & Curso & Disciplina & $\begin{array}{c}\text { Carga } \\
\text { horária }\end{array}$ & Período & Ementa \\
\hline 鳬 & $\begin{array}{l}\text { Educação } \\
\text { física }\end{array}$ & $\begin{array}{c}\text { Libras - } \\
\text { língua } \\
\text { brasileira } \\
\text { de sinais }\end{array}$ & $60 \mathrm{~h}$ & $8^{\circ}$ & $\begin{array}{l}\text { O sujeito surdo: conceitos, cultura e } \\
\text { a relação histórica da surdez com a } \\
\text { língua de sinais; análise das tendências } \\
\text { educacionais: segregação, inclusão e } \\
\text { bilinguismo. Noções linguísticas de } \\
\text { Libras: aspectos lógicos, morfológicos } \\
\text { e gramaticais (sintaxe). Noções } \\
\text { básicas contextualizadas de língua } \\
\text { de sinais. Análise do processo de } \\
\text { tradução e interpretação: Libras- } \\
\text { português, português-Libras. } \\
\text { O papel do intérprete. A leitura e } \\
\text { a escrita dos surdos. Avaliação da } \\
\text { produção dos alunos surdos em } \\
\text { suas mais diversas manifestações. }\end{array}$ \\
\hline $\begin{array}{l}0 \\
\text { 车 }\end{array}$ & Química & $\begin{array}{c}\text { Língua } \\
\text { brasileira } \\
\text { de sinais }\end{array}$ & $51 \mathrm{~h}$ & $4^{\circ}$ & $\begin{array}{l}\text { A história da surdez e a educação } \\
\text { do sujeito surdo no Brasil: } \\
\text { questões sobre o programa de } \\
\text { inclusão. Teorias linguísticas sobre } \\
\text { a aquisição da linguagem pela } \\
\text { criança surda e o estatuto da língua } \\
\text { brasileira de sinais (Libras). A } \\
\text { língua brasileira de sinais e escrita. }\end{array}$ \\
\hline 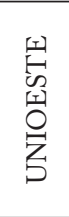 & Geografia & Libras & $68 \mathrm{~h}$ & $6^{\circ}$ & $\begin{array}{l}\text { Desenvolvimento das habilidades } \\
\text { necessárias para aquisição da } \\
\text { Libras - a língua de modalidade } \\
\text { visual e gestual, baseada em regras } \\
\text { gramaticais da língua de sinais e } \\
\text { do segmento das pessoas surdas. }\end{array}$ \\
\hline 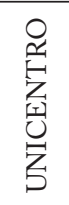 & Física & $\begin{array}{l}\text { Noções } \\
\text { de língua } \\
\text { brasileira } \\
\text { de sinais }\end{array}$ & $68 \mathrm{~h}$ & $8^{\circ}$ & $\begin{array}{l}\text { Retrospectiva histórica sobre os } \\
\text { surdos, sua língua, sua cultura e } \\
\text { sua identidade. O ensino de Libras } \\
\text { em contexto. Noção básica de } \\
\text { aspectos linguísticos de Libras. }\end{array}$ \\
\hline 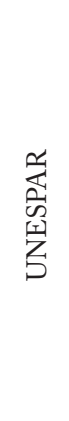 & Artes visuais & Libras & $68 \mathrm{~h}$ & $8^{\circ}$ & $\begin{array}{l}\text { O sujeito surdo: conceitos, cultura } \\
\text { e a relação histórica da surdez } \\
\text { com a língua de sinais. Noçães } \\
\text { linguísticas de Libras: parâmetros, } \\
\text { classificadores e intensificadores no } \\
\text { discurso. A gramática da língua de } \\
\text { sinais. Aspectos sobre a educação } \\
\text { de surdos. Teoria da tradução e } \\
\text { interpretação. Técnicas de tradução } \\
\text { em Libras-português; técnicas de } \\
\text { tradução português-Libras. Noções } \\
\text { básicas da língua de sinais brasileira. }\end{array}$ \\
\hline
\end{tabular}

Fonte: Projetos pedagógicos/2015.

Elaboração do autor. 
contexto, representa a positivação pública de coletivos passíveis de agenciamento e merecedores de atenção por parte dos atuais modelos inclusivos de escolarização (Carniel, 2013).

Como evidenciam as ementas analisadas, as perspectivas acadêmicas que justificaram o estatuto linguístico da língua de sinais na década de 1980 (Quadros, 2012) e o estudo sociocultural da surdez, que se disseminou no país ao longo dos anos de 1990 (Skliar, 1998), sustentam conteúdos formativos que descrevem a presença política da surdez enquanto uma categoria étnica e linguística (Assis Silva, 2012; Brito, 2013). Tal movimento curricular tem o potencial de enfraquecer nas salas de aula do ensino superior as tradicionais concepções biomédicas acerca da deficiência auditiva e estabelecer pontos de vista diversos sobre as capacidades cognitivas, linguísticas e sociais da população surda. Essa reviravolta nos discursos sobre a surdez e a Libras parece também deslocar as discussões a respeito da inclusão educacional das pessoas surdas dos campos especializados da educação especial para recontextualizá-las no conjunto da diversidade humana que atualmente configura a educação básica brasileira.

É verdade que os conteúdos desse aprendizado ainda não foram estabelecidos por nenhuma diretriz nacional, ao menos não até o presente momento. Contudo, a exemplo do que outras pesquisas sobre o tema também já indicaram (Lemos e Chaves, 2012; Vitaliano, Dall'Acqua e Brochado, 2013), por meio do exame da organização curricular da Libras percebe-se a estratégia de articular o estudo da gramática formal com o estudo sociocultural da surdez. Desse modo, aspectos linguísticos agregam-se a dimensões antropológicas, filosóficas, históricas, jurídicas, políticas ou sociológicas da Libras, o que indica certa abertura curricular para abordar os conteúdos dessas disciplinas a partir de suas relações com as produções culturais, as experiências sociais e educacionais ou mesmo com as principais realizações políticas dos coletivos em defesa da língua de sinais que atuaram no país durante as últimas décadas.

Nesse ritmo, cursos e departamentos oferecem a todo um contingente de futuros professores e professoras que irão se formar para atuar na educação básica uma experiência mínima com a Libras e um contato inicial com a própria história social e cultural que levou ao reconhecimento identitário das pessoas surdas. Sinaliza-se, assim, uma preocupação comum de profissionais envolvidos na elaboração dessas ementas em considerar tanto os fundamentos linguísticos quanto os aspectos normativos, pedagógicos e sociais que envolvem a inclusão das comunidades surdas nos sistemas regulares de ensino. Trata-se de uma proposta curricular há muito almejada pelos coletivos da área (Lana Júnior, 2010; Monteiro, 2006), justamente por apontar para a conscientização sobre a situação dessas pessoas nas redes escolares do país, favorecendo certa instrumentalização básica na língua de sinais.

O desafio, entretanto, parece residir no caráter "genérico" dos conteúdos listados por essas ementas, que podem isolar e descontextualizar a disciplina do restante dos conhecimentos especializados dos cursos em que estão inseridas. Em outras palavras, por mais que a Libras atualmente divida espaço com outras disciplinas nas grades curriculares dos graduandos e graduandas que cursam as licenciaturas paranaenses, nada assegura que essa presença não será "folclorizada"(Martins, 2012). 
Afinal, em que medida a Libras estaria conseguindo dialogar com os conteúdos específicos desses cursos de formação docente? Sua enunciação realmente poderá dialogar com as tradições teóricas de outras áreas ou, inversamente, ela figurará apenas enquanto manifestação "exótica" e radicalmente distinta dos conhecimentos habitualmente apresentados aos licenciandos e licenciandas desses cursos?

Tais conteúdos evidentemente variam de um plano de ensino para outro, pois a sua organização depende dos interesses das próprias instituições que os oferecem, bem como dos perfis dos professores e professoras encarregados das aulas (Rossi, 2010). Por isso mesmo, para seguir com a problematização proposta, foram selecionados exemplos concretos dessa organização curricular. No Quadro 2 estão dispostos os objetivos, os conteúdos programáticos e as bibliografias básicas indicadas em dois planos de ensino que foram elaborados em 2010 para as disciplinas de Libras nas licenciaturas de ciências biológicas e de matemática. Trata-se de uma tentativa de analisar o modo como esses conteúdos curriculares estão sendo planejados a partir do cotejamento entre dois programas específicos. A intenção não é compará-los para avaliar seu mérito, mas observar neles o modo como são configuradas certas ideias de língua, surdez e inclusão.

De uma maneira geral, é possível observar que a organização pedagógica desses planos reforça tanto a percepção de um vínculo entre língua e cultura na enunciação do sujeito surdo enquanto uma categoria social emergente quanto o sentimento de "desconexão" com os demais conteúdos curriculares dos cursos em que foram implantados, conforme sugerido anteriormente pelas próprias ementas curriculares. No primeiro deles, voltado à licenciatura de ciências biológicas da UFPR, os objetivos de desmistificar preconceitos e estereótipos, compreender fundamentos teóricos e marcos legais e oportunizar a interação com pessoas surdas integram-se ao estudo linguístico dos parâmetros constitutivos da Libras. As referências básicas acompanham tais conteúdos, indicando também a leitura da lei de Libras, de 2002, e do decreto federal n. 5.626, de 2005. Conforma-se, assim, um horizonte de valorização da Libras como um elemento relevante no processo de inclusão educacional de falantes da língua de sinais nos sistemas regulares de ensino da educação básica.

No caso das disciplinas de Libras 1 e Libras 2, ofertadas à licenciatura em matemática da UTFPR, embora apresentadas de forma mais instrumental, essas perspectivas são igualmente evidentes. No primeiro semestre estão previstos conteúdos básicos para uma compreensão sociolinguística da Libras, bem como para o entendimento dos parâmetros gerais de sua estrutura gramatical. No segundo, tais conteúdos são aprofundados com o objetivo de subsidiar a utilização dessa língua. As bibliografias indicadas para a disciplina de Libras 1 estão concentradas na aprendizagem de aspectos linguísticos da língua de sinais. Desse modo, percebe-se uma tentativa de organizar um planejamento que valorize a inclusão educacional das comunidades surdas no Brasil e instrumentalize futuros professores e professoras para o uso da Libras em contextos formais e informais de diálogo.

Portanto, verifica-se que ambos os planos de ensino constroem, por caminhos diversos, a disciplina de Libras enquanto um espaço de reconhecimentos e experimentações que oportunizarão formações básicas para docentes que se relacionarão 
Quadro 2 - Organização dos planos de ensino de Libras

\begin{tabular}{|c|c|c|c|c|c|}
\hline \multirow[b]{2}{*}{ IES } & \multicolumn{5}{|c|}{ Plano de ensino } \\
\hline & Curso & Disciplina & Objetivos & $\begin{array}{c}\text { Conteúdos } \\
\text { programáticos }\end{array}$ & $\begin{array}{c}\text { Bibliografia } \\
\text { básica }\end{array}$ \\
\hline 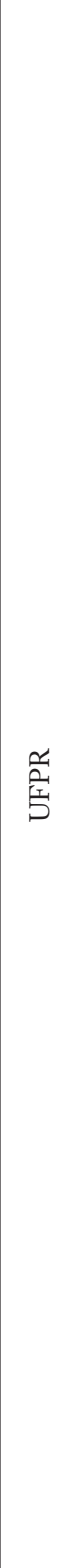 & 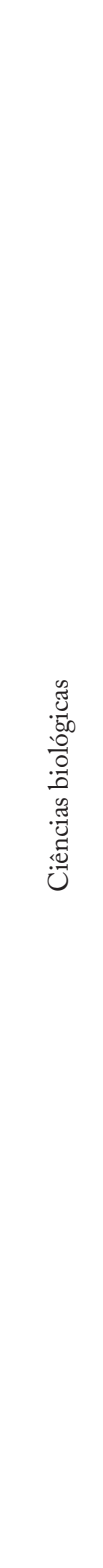 & 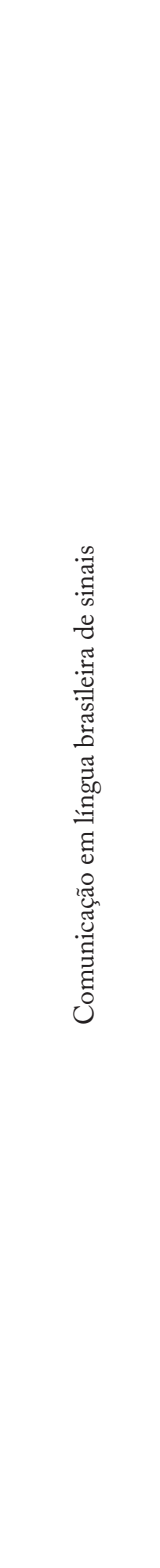 & $\begin{array}{c}\text { Desmistificar } \\
\text { preconceitos e } \\
\text { estereótipos sobre } \\
\text { a surdez e as } \\
\text { pessoas surdas; } \\
\text { Conhecer os } \\
\text { fundamentos } \\
\text { filosóficos, teóricos e } \\
\text { legais da educação de } \\
\text { surdos no contexto das } \\
\text { políticas de inclusão; } \\
\text { Aprofundar } \\
\text { conhecimentos } \\
\text { teórico-metodológicos } \\
\text { relacionados à educação } \\
\text { bilíngue para surdos; } \\
\text { Realizar estudos } \\
\text { teórico-práticos sobre } \\
\text { a língua brasileira de } \\
\text { sinais, oportunizando } \\
\text { a interação com } \\
\text { pessoas surdas; } \\
\text { Compreender } \\
\text { os parâmetros } \\
\text { constitutivos da Libras } \\
\text { e sua importância } \\
\text { em processos } \\
\text { visuais-espaciais } \\
\text { de comunicação; } \\
\text { Contribuir para a } \\
\text { inclusão social das } \\
\text { pessoas surdas por meio } \\
\text { da difusão da Libras } \\
\text { nos cursos de ensino } \\
\text { superior, conforme } \\
\text { prevê o decreto federal } \\
\text { n. 5.626/2005. }\end{array}$ & $\begin{array}{l}\text { Aspectos conceituais } \\
\text { da surdez e das } \\
\text { comunidades surdas; } \\
\text { História e educação } \\
\text { de surdos; } \\
\text { Movimentos } \\
\text { Surdos, cultura e } \\
\text { comunidades surdas; } \\
\text { Educação de surdos } \\
\text { no contexto das } \\
\text { políticas inclusivas: } \\
\text { diretrizes legais e } \\
\text { político-pedagógicas; } \\
\text { Fundamentos teórico- } \\
\text { metodológicos da } \\
\text { educação bilíngue } \\
\text { para surdos; } \\
\text { Linguagem e } \\
\text { cognição de } \\
\text { crianças surdas; } \\
\text { Fundamentos legais e } \\
\text { teóricos da educação } \\
\text { bilíngue para surdos } \\
\text { no contexto das } \\
\text { políticas inclusivas; } \\
\text { Língua Brasileira } \\
\text { de Sinais - Libras: } \\
\text { aspectos históricos e } \\
\text { culturais; parâmetros } \\
\text { formadores primários } \\
\text { e secundários; } \\
\text { variações e } \\
\text { empréstimos } \\
\text { linguísticos; } \\
\text { diferenças e } \\
\text { semelhanças } \\
\text { estruturais com a } \\
\text { língua portuguesa. }\end{array}$ & $\begin{array}{l}\text { BRASIL. } \\
\text { Decreto federal } \\
\text { n. 5.626/2005. } \\
\text { Regulamenta a } \\
\text { Lei de Libras } \\
\text { e dá outras } \\
\text { providências. } \\
\text { FERNANDES, } \\
\text { S.; STROBEL, K. } \\
\text { Aspectos linguisticos } \\
\text { da lingua } \\
\text { brasileira de sinais. } \\
\text { Curitiba: SEED/ } \\
\text { DEE, 1998. } \\
\text { Lei federal n. } \\
\text { 10.436/2002. } \\
\text { Brasília: MEC, } \\
\text { 2002. } \\
\text { LIRA, G. A.; } \\
\text { FELIPE T. A. } \\
\text { Dicionário da } \\
\text { lingua brasileira } \\
\text { de sinais. Brasília: } \\
\text { CORDE, 2001. } \\
\text { SKLIAR, } \\
\text { C. (Org.). } \\
\text { Atualidades na } \\
\text { educação bilingue } \\
\text { para surdos. } \\
\text { Porto Alegre: } \\
\text { Mediação, 1999. }\end{array}$ \\
\hline
\end{tabular}

Continua... 
Quadro 2-Continuação

\begin{tabular}{|c|c|c|c|c|c|}
\hline \multirow[b]{2}{*}{ IES } & \multicolumn{5}{|c|}{ Plano de ensino } \\
\hline & Curso & Disciplina & Objetivos & $\begin{array}{c}\text { Conteúdos } \\
\text { programáticos }\end{array}$ & $\begin{array}{c}\text { Bibliografia } \\
\text { básica }\end{array}$ \\
\hline \multirow[b]{2}{*}{$\begin{array}{l}\text { 品 } \\
\text { 至 } \\
\text { 占 }\end{array}$} & \multirow[b]{2}{*}{ 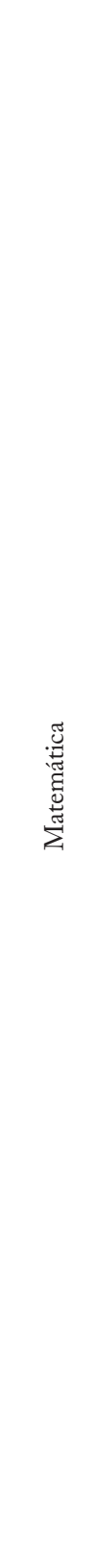 } & 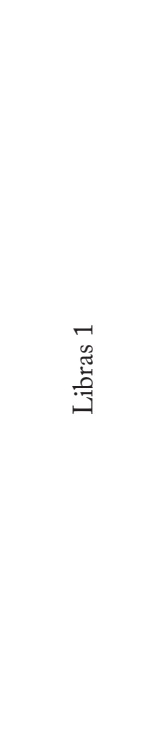 & $\begin{array}{c}\text { Instrumentalizar } \\
\text { os alunos para o } \\
\text { estabelecimento de uma } \\
\text { comunicação funcional } \\
\text { com pessoas surdas; } \\
\text { Favorecer a inclusão } \\
\text { da pessoa surda no } \\
\text { contexto escolar; } \\
\text { Difusão e valorização } \\
\text { da Libras na } \\
\text { comunidade escolar e } \\
\text { sociedade em geral; } \\
\text { Reconhecer os diferentes } \\
\text { profissionais que atuam } \\
\text { na educação de surdos. }\end{array}$ & \begin{tabular}{|} 
Diferentes línguas \\
de sinais; \\
Status da língua de \\
sinais no Brasil; \\
Cultura surda; \\
Sistema de transcrição \\
da língua portuguesa \\
para a língua de sinais; \\
Vocabulário em \\
língua de sinais; \\
Variação linguística; \\
Parâmetros da língua \\
de sinais: morfologia; \\
sintaxe e semântica; a \\
expressão corporal como \\
elemento linguístico.
\end{tabular} & \begin{tabular}{|} 
CAPOVILLA, \\
F.; RAPHAEL, \\
W. D. Dicionário \\
enciclopédico \\
ilustrado trilingue \\
da lingua de sinais \\
brasileira. São Paulo: \\
EDUSP, 2001. \\
FELIPE, T. A. \\
Libras em contexto: \\
curso básico, livro do \\
estudante. Brasília: \\
SEESP, 2006. \\
\\
QUADROS, R. \\
M.; KARNOPP, \\
L. B. Lingua de \\
sinais brasileira. \\
Porto Alegre: \\
Artmed, 2004.
\end{tabular} \\
\hline & & 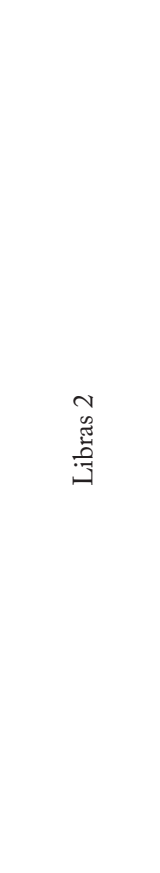 & $\begin{array}{l}\text { Criar diálogo utilizando } \\
\text { advérbios de tempo e } \\
\text { expressões relacionados } \\
\text { ao ano sideral; } \\
\text { Utilizar os números } \\
\text { cardinais e ordinais em } \\
\text { contextos diversos; } \\
\text { Utilizar a negação } \\
\text { incorporada e ações } \\
\text { continuadas; } \\
\text { Reconhecer os sinais } \\
\text { referentes a profissões e } \\
\text { cargos, identificando os } \\
\text { ambientes de trabalho; } \\
\text { Criar contextos utilizando } \\
\text { sinais relacionados à } \\
\text { profissão, trabalho e } \\
\text { meios de comunicação; } \\
\text { Utilizar alguns pronomes } \\
\text { interrogativos e os } \\
\text { pronomes indefinidos. }\end{array}$ & \begin{tabular}{|c|} 
Cultura surda e a \\
produção literária; \\
Emprego da Libras \\
em situações \\
discursivas formais; \\
Cultura e identidade \\
surda; \\
Vivências práticas para \\
o desenvolvimento \\
dos parâmetros da \\
Libras: configuração \\
de mão, movimento, \\
direcionalidade, ponto \\
de articulação, expressão \\
corporal e facial.
\end{tabular} & $\begin{array}{c}\text { Sem indicação } \\
\text { bibliográfica }\end{array}$ \\
\hline
\end{tabular}

Fonte: Planos de ensino/2010.

Elaboração do autor. 
com a língua de sinais como uma segunda língua. $\mathrm{O}$ modo pelo qual esses conteúdos integrarão as trajetórias acadêmicas desses estudantes, todavia, dependerá da própria formação inicial dos docentes de Libras e dos desafios por eles enfrentados nas instituições de ensino superior do país. Por isso mesmo, parece premente que estudos sobre o tema comecem a indagar em que medida as atuais políticas de preparação e de seleção de docentes para ministrar a disciplina de Libras estão conseguindo oferecer condições acadêmicas para modificar não apenas o estatuto social da surdez e da língua de sinais, mas principalmente a sua posição epistemológica no interior das práticas dominantes de produção do conhecimento de cada área.

Por enquanto, com base na análise das ementas curriculares e dos planos de ensino de algumas das principais universidades paranaenses, é possível compreender que estudantes formados nos marcos da legislação vigente terão uma ideia geral de um universo social e comunicacional até então ignorado pela maioria das pessoas. Quando tiverem a oportunidade de lecionar na educação básica para falantes da língua de sinais, talvez consigam se comunicar, mas ainda dependerão da presença de intérpretes que realizem a mediação entre o que precisa ser explicado e o que pode ser compreendido. Essa constatação não desmerece o fato de que a inclusão da Libras foi uma conquista histórica para os coletivos surdos, pois as políticas linguísticas vigentes já promoveram uma reviravolta discursiva em torno da surdez e da Libras no universo acadêmico brasileiro. Porém, perceber o modo como tal disciplina está sendo estruturada no interior dessas instituições nos auxiliará a compreender o tipo de inclusão que o decreto federal n. 5.626 de 2005 pôde fabricar; para modificá-la, entretanto, outras ferramentas serão necessárias. Afinal, a exemplo do que já afirmou Quadros (2006, p. 158-159), "o espaço de negociação começa a ser deflagrado, [...] a partir dessas experiências [...] pode ser processada uma aproximação entre o 'querer' e o fazer na educação".

\section{CONSIDERAÇÕES FINAIS}

Quem está se formando para atuar no magistério da educação básica pode ainda nem ter percebido, mas a recente inclusão da Libras na grade curricular das instituições de ensino superior do país representou uma reviravolta nos discursos especializados que vêm modificando os sentidos e os significados atribuídos à surdez e à língua de sinais. Gradativamente instituída como disciplina obrigatória em todas as licenciaturas do país, a Libras hoje ocupa espaços que há pouco tempo eram impraticáveis para ela. Isso porque o reconhecimento acadêmico, pedagógico e social dessa língua somente pôde ocorrer após intensas mobilizações em torno da transformação de seu estatuto linguístico. Nesse processo, as supostas "limitações" ou "imperfeições" historicamente atribuídas às pessoas surdas puderam ser contestadas, abrindo terreno ao estabelecimento de uma perspectiva sócio-cultural que reconfigurou a surdez em uma particularidade étnico-linguística passível de inclusão por parte de todos os níveis de ensino.

Como procurei argumentar, por meio do decreto federal n. 5.626, de 2005, um caminho para produzir essa inclusão foi traçado. Dele participarão docentes das mais diversas áreas, formados nos marcos dessa política linguística que pretende 
educar pessoas surdas falantes da língua de sinais como uma parcela da diversidade cultural hoje abrigadas nas escolas e nos colégios regulares da educação básica. Desse modo, espera-se que esses professores e professoras não se surpreendam com a presença dessa categoria social e criem meios para promover a sua inclusão. No entanto, corre-se o risco de que suas capacidades comunicativas e pedagógicas permaneçam limitadas ao aprendizado que lhes foi oferecido - um aprendizado inicial e genérico. Nesse caso, o anseio por uma educação bilíngue, segundo a qual a Libras seja pensada enquanto uma língua natural e a língua portuguesa como uma segunda língua, ainda parece uma realidade distante.

\section{REFERÊNCIAS}

Assis Silva, C. A. Cultura surda: agentes religiosos e a construção de uma identidade. São Paulo: Terceiro Nome, 2012.

Brasil. Senado Federal. Projeto de Lei n. 131, de 13 de junho de 1996. Dispõe sobre a Língua Brasileira de Sinais - Libras e dá outras providências. Diário do Senado Federal, n. 106, 14 jun. 1996, p. 9.913.

.Presidência da República. Lei n. 10.436, de 24 de abril de 2002. Dispõe sobre a Língua Brasileira de Sinais - Libras e dá outras providências. Diário Oficial da União, Brasília: Ministério da Educação, 2002.

. Presidência da República. Decreto n. 5.626, de 22 de dezembro de 2002. Regulamenta a lei n. 10.436, de 24 de abril de 2002, que dispõe sobre a Língua Brasileira de Sinais - Libras, e o art. 18 da lei n. 10.098, de 19 de dezembro de 2000. Diário Oficial da União, Brasília: Ministério da Educação, 2005.

B RITo, F. B. O movimento social surdo e a campanha pela oficialização da língua de sinais. 2013. Tese (Doutorado em Educação) — Universidade Estadual de São Paulo, São Paulo, 2013. Brito, F. B.; Neves, S. L. G.; Xavier, A. N. O movimento surdo e sua luta pelo reconhecimento da Libras e pela construção de uma política linguística no Brasil. In: Albres, N. A.; Neves, S. L. G. (Orgs.). Libras em estudo: política linguística. São Paulo: FENEIS, 2013. p. 67-103.

Brito, L. F. Similarities \& differences in two Brazilian sign languages. Sign Language Studies, Washington, DC: Gallaudet University Press, v. 42, n. 1, p. 45-56, 1984.

. Epistemic, alethic, and deontic modalities in a Brazilian Sing Language. In: Fischer, S.; Siple, P. (Eds.). Theoretical issues in sign language research. Chicago: Chicago University Press, 1990.v. 1, p. 229-260.

. Por uma gramática da língua de sinais. Rio de Janeiro: Tempo Brasileiro, 1995.

CANDAU, V. M. Direitos humanos, educação e interculturalidade: as tensões entre igualdade e diferença. Revista Brasileira de Educação, Rio de Janeiro: ANPEd; Campinas: Autores Associados, v. 13, n. 37, p. 45-56, jan./abr. 2008.

CArniel, F. A invenção (pedagógica) da surdez: sobre a gestão estatal da educação especial na primeira década do século XXI. 2013. Tese (Doutorado em Sociologia Política) Universidade Federal de Santa Catarina, Florianópolis, 2013. 
Felipe, T. A. Políticas públicas para a inserção da Libras na educação de surdos. Espaço: Informativo Técnico-Científico do INES, Rio de Janeiro: INES, v. 1, n. 25, p. 33-47, jan./jun. 2006.

Lana Júnior, M. C. M. História do movimento político das pessoas com deficiência no Brasil. Brasília: Secretaria de Direitos Humanos, 2010.

Larrosa, J. Notas sobre a experiência e o saber de experiência. Revista Brasileira de Educação, Rio de Janeiro: ANPEd; Campinas: Autores Associados, v. 1, n. 19, p. 20-28, jan./abr. 2002.

Lemos, A. M.; Chaves, E. P. Disciplina de Libras no ensino superior: da proposição à prática de ensino como segunda língua. In: Encontro Nacional de Didática e Práticas de Ensino, 16., 2012, Campinas. Anais... Campinas: UNICAMP, 2012.

Martins, V. R. O. Análise das vantagens e desvantagens da Libras como disciplina curricular no ensino superior. Cadernos do CEOM, Chapecó: UnoChapecó, v. 21, n. 28, p. 191-206, 2008.

. O acontecimento do ensino de Libras: diferenças e resistência. In: Albres, $N$. A. (Org.). Libras em estudo: ensino-aprendizagem. São Paulo: FENEIS, 2012. p. 37-54. Martins, V. R. O.; Nascimento, L. C. R. Algumas análises da disciplina de Libras nos cursos de licenciatura: reflexões e desdobramentos. Intellectus, Jaguariúna: UNIFAJ, v. 3, n. 31, p. 15-37, jun./set. 2015.

Monteiro, M. S. História dos movimentos dos surdos e reconhecimento da Libras no Brasil. EDT: Educação Temática Digital, Campinas: UNICAMP, v. 7, n. 2, p. 292-305, jun. 2006.

Quadros, R. M. Políticas linguísticas e educação de surdos em Santa Catarina: espaço de negociações. Cadernos Cedes, Campinas: UNICAMP, v. 26, n. 69, p. 141-161, maio/ ago. 2006.

Estudos de língua de sinais: uma entrevista com Ronice Müller de Quadros. Revista Virtual de Estudos da Linguagem - ReVEL, [S.1.: s.n.], v. 10, n. 19, s/p. ago. 2012.

Quadros, R. M.; Stumpf, M. R. O primeiro curso de graduação em letras língua brasileira de sinais: educação à distância. ETD - Educação Temática Digital, Campinas: UNICAMP, v. 10, n. 2, p. 169-185, jun. 2009.

Rossı, R. A. A Libras como disciplina no ensino superior. Revista de Educação, Valinhos: Anhanguera Educacional, v. 13, n. 15, p. 71-85, out. 2010.

SkLiar, C. Os estudos surdos em educação: problematizando a normalidade. In:

(Org.). A surdez: um olhar sobre as diferenças. Porto Alegre: Mediação, 1998. p. 7-32.

Souza, R. M. Que palavra que te falta? Linguística e educação: considerações epistemológicas a partir da surdez. São Paulo: Martins Fontes, 1998.

. Língua de sinais e escola: considerações a partir do texto de regulamentação da língua brasileira de sinais. ETD — Educação Temática Digital, Campinas: UNICAMP, v. 7, n. 2, p. 266-281, jun. 2006.

Stainer, G. Os livros que não escrevi. Lisboa: Gradiva,2008. 
Strobel, K. A visão histórica da in(ex)clusão dos surdos nas escolas. ETD - Educação Temática Digital, Campinas: UNICAMP, v. 7, n. 2, p. 243-252, jun. 2006.

Vitaliano, C. R.; Dall'acqua, M. J. C.; Brochado, S. M. D. A disciplina língua brasileira de sinais nos currículos dos cursos de pedagogia. Boletim Técnico do SENAC, Rio de Janeiro: SENAC, v. 39, n. 2, p. 106-121, maio/ago. 2013.

\section{SOBRE O AUTOR}

Fagner Carniel é doutor em sociologia política pela Universidade Federal de Santa Catarina (UFSC). Professor da Universidade Estadual de Maringá (UEM).

E-mail: fagnercarniel@yahoo.com.br

Recebido em 4 de abril de 2016

Aprovado em 27 de setembro de 2016 